\title{
Noradrenergic symptom cluster in depression
}

\author{
This article was published in the following Dove Press journal: \\ Neuropsychiatric Disease and Treatment \\ 3I May 20I I \\ Number of times this article has been viewed
}

\author{
Stuart Montgomery' \\ Mike Briley ${ }^{2}$ \\ 'Imperial College School \\ of Medicine, London, UK; \\ ${ }^{2}$ NeuroBiz Consulting and \\ Communication, Castres, France
}

Correspondence: Mike Briley NeuroBiz Consulting and Communication, 27 Impasse des Grèses, 8I I00 Castres, France

Tel +335637l 0323

Email mike.briley@neurobiz.com

\section{Introduction}

Depression is characterized by a wide range of diverse symptoms, the severity of which can be quantified by various depression rating scales, such as the Montgomery Asberg Depression Rating Scale. Analyses of the individual items of this scale in patients treated with the selective serotonin reuptake inhibitors (SSRIs) have shown that not all items respond equally or with the same time of onset of improvement (Table 1). ${ }^{1,2}$ The items which respond less well or more slowly with SSRIs include lassitude, loss of energy, retardation of thoughts or actions, as well as concentration difficulties and loss of alertness. The loss of interest or pleasure that depressed patients experience (anhedonia) also responds poorly to SSRIs, and patients often complain of emotional indifference or blunting. Certain sleep difficulties are sometimes worsened by SSRIs. Appetite loss can be aggravated by certain SSRIs, an effect which can be made worse by nausea at the beginning of treatment.

Similarly, a cluster of common depressive symptoms of "decreased positive affect", including loss of interest or pleasure, fatigue, loss of energy, and decreased motivation, which do not respond adequately to serotonergic antidepressants, have been identified. Antidepressants that enhance noradrenergic (and dopaminergic) activity appear to offer a therapeutic advantage over serotonergic antidepressants in the treatment of these symptoms. ${ }^{3}$

Based mainly on theoretical considerations, the symptoms of depression have been associated with deficiencies of one or more of the monoamine neurotransmitters. ${ }^{4}$ In this scheme, decreased concentration, retardation, loss of energy, lassitude, tiredness, and reduced self-care are associated with decreased noradrenergic activity (Table 1). Thus, clinical and theoretical considerations combine to define the noradrenergic symptom cluster, ie, decreased concentration, retardation, loss of energy, lassitude, tiredness, and reduced self-care.

This supplement, which is based on a symposium held at the International Forum on Mood and Anxiety at Vienna in November 2010, discusses the noradrenergic symptom cluster, the importance of these symptoms in the burden of depression, their clinical and neuropharmacological nature, and how these symptoms can be improved by the serotonin and noradrenaline reuptake inhibitor (SNRI) antidepressant, milnacipran.

In the first paper, Lépine presents recent epidemiological data on the prevalence of depression and the associated risk of mortality by suicide, as well as cardiovascular and other deaths. Studies of the familial and financial burden of depression show an submit your manuscript | www.dovepress.com

Dovepress

DOI: 10.2147/NDT.S1961।
Neuropsychiatric Disease and Treatment 20 I I:7 (SuppI I) I-2

(C) 201 I Montgomery and Briley, publisher and licensee Dove Medical Press Ltd. This is an Open Access article which permits unrestricted noncommercial use, provided the original work is properly cited. 
Table I Comparison of core symptoms of depression which respond less well or more slowly to SSRIs and depressive symptoms specifically related to a deficiency of noradrenergic neurotransmission

A. Core symptoms of depression which respond less well or more slowly to SSRIs

- Lassitude

- Loss of energy

- Retardation of thoughts and actions

- Concentration difficulties, loss of alertness

- Loss of interest, anhedonia, emotional indifference or blunting

- Sleep difficulties, sometimes worsened by SSRIs

- Appetite loss, sometimes worsened by nausea caused by SSRIs

B. Depressive symptoms specifically related to a deficiency of noradrenergic neurotransmission

- Lassitude

- Loss of energy

- Retardation of thoughts and actions

- Concentration difficulties, loss of alertness

- Tiredness

Abbreviation: SSRIs, selective serotonin reuptake inhibitors.

increased risk of loss of productivity and absenteeism in depression, which frequently result in decreased income or unemployment. The importance of the burden of depression is underlined by the estimation of the World Health Organization that, by 2030, unipolar major depression will become the leading worldwide cause of disease burden.

The second paper by Moret examines the importance of norepinephrine in the etiology of depression. Evidence for the involvement of norepinephrine including recent studies on neuronal pathways and symptoms, highlights the determinant role of norepinephrine in key symptoms, including executive functioning, which regulates cognition, motivation, and intellect, which are of fundamental importance in social relationships, that are impoverished in depression.

In the third paper, Blier explains the reciprocal interactions between the serotonin system and norepinephrine and dopamine neurotransmission. Enhanced serotonin transmission, as during SSRI treatment, attenuates noradrenergic and dopaminergic activity. This can contribute to the residual symptoms of fatigue and lack of energy that are often reported by patients responding to SSRI. Milnacipran, by increasing norepinephrine (and dopamine), as well as serotonin neurotransmission is less likely to induce or aggravate such residual symptoms. Milnacipran's potentiation of norepinephrine and serotonin (and indirectly dopamine) neurotransmission contributes to its antidepressant action, while its attenuation of phasic noradrenergic reactivity reduces the risk of anxiety.

In the fourth and final paper, Kasper discusses the importance of social dysfunction in depressed patients which can lead to family disruption, social isolation, absenteeism, and potential unemployment. The symptoms of the noradrenergic symptom cluster are important factors in social dysfunction, and antidepressants with a strong noradrenergic component improve social functioning. Preliminary data suggest that milnacipran improves social functioning to a greater extent than SSRIs.

\section{Disclosure}

Professor Stuart Montgomery has received honoraria from AstraZeneca, Bionevia, Bristol Myers Squibb, GlaxoSmithKline, Johnson \& Johnson, Lilly, Lundbeck, Merck, Merz, M's Science, Neurim, Otsuka, Pierre Fabre Médicament, Pfizer, Pharmaneuroboost, Richter, Roche, Sanofi, Sepracor, Servier, Shire, Synosis, Takeda, Theracos, Targacept, Transcept, UBC, Xytis, and Wyeth. Dr Mike Briley is a consultant for Pierre Fabre Médicament, Asahi Kasei Pharma, Germania Pharmaceutica, Janssen Pharmaceutica, and Cypress BioScience.

\section{References}

1. Bech P, Tanghøj P, Andersen HF, Overø K. Citalopram dose-response revisited using an alternative psychometric approach to evaluate clinical effects of four fixed citalopram doses compared to placebo in patients with major depression. Psychopharmacology (Berl). 2002;163:20-25.

2. Wade A, Friis Andersen H. The onset of effect for escitalopram and its relevance for the clinical management of depression. Curr Med Res Opin. 2006;22:2101-2110.

3. Nutt D, Demyttenaere K, Janka Z, et al. The other face of depression, reduced positive affect: The role of catecholamines in causation and cure. J Psychopharmacol. 2007;21:461-471.

4. Nutt DJ. Relationship of neurotransmitters to the symptoms of major depressive disorder. J Clin Psychiatry. 2008;69 Suppl E1:4-7.
Neuropsychiatric Disease and Treatment

\section{Publish your work in this journal}

Neuropsychiatric Disease and Treatment is an international, peerreviewed journal of clinical therapeutics and pharmacology focusing on concise rapid reporting of clinical or pre-clinical studies on a range of neuropsychiatric and neurological disorders. This journal is indexed on PubMed Central, the 'PsycINFO' database and CAS, and is the official

\section{Dovepress}

journal of The International Neuropsychiatric Association (INA). The manuscript management system is completely online and includes a very quick and fair peer-review system, which is all easy to use. Visit http://www.dovepress.com/testimonials.php to read real quotes from published authors. 